\title{
ethic@

\section{A QUESTÃO DA MULHER EM ROUSSEAU E AS CRÍTICAS DE MARY WOLLSTONECRAFT}

\author{
DISCUSSING THE PROBLEM OF WOMAN ON ROUSSEAU AND \\ WOLLSTONECRAFT
}

\section{WILSON ALVES DE PAIVA ${ }^{1}$}

(UFG, Brasil)

\begin{abstract}
RESUMO
Rousseau foi um dos maiores expoentes da intelectualidade europeia do século XVIII e que, juntamente com os demais, não escapou de reproduzir em seus escritos a visão da família patriarcal, sobretudo no Emílio. Wollstonecraft foi uma escritora e filósofa inglesa, conhecida defensora dos direitos das mulheres, que criticou Rousseau. O presente texto procura discutir diferenças e aproximações entre os dois, buscando ressaltar que o filósofo genebrino contribuiu com o debate, mesmo sem ter discutido o tema diretamente. Também procura demonstrar que é um equívoco interpretá-lo como um anti-feminista ou alguém que tenha sido contrário à educação da mulher, tal como o fez Wollstonecraft em seu livro $A$ vindication of the rights of woman.

Palavras-chave: Rousseau, Wollstonecraft, formação da mulher, educação no século XVIII.
\end{abstract}

\section{ABSTRACT}

Rousseau is one of the greatest exponents of the Eighteenth century philosophy and who, among others, did not escape from reproducing the vision of the patriarchal family, especially on the book Emile. Wollstonecraft was an English writer and philosopher, a well-known advocate for women's rights, who criticized Rousseau. The present text seeks to discuss differences and approximations between them, seeking to emphasize that the Genevan philosopher contributed to the debate, even without discussing the topic directly. It also seeks to demonstrate that it is a misconception to see him as an anti-feminist or someone who has been opposed to the education of women, as Wollstonecraft did in his book A Vindication of the Rights of Woman.

Key words: Rousseau, Wollstonecraft, women's education, educational thought in the Eighteenth century.

\section{Introdução}

O filósofo genebrino Jean-Jacques Rousseau (1712-1778) é conhecido como um crítico da desigualdade e um defensor da liberdade. Em suas obras políticas, com destaque para o Contrato Social e o Discurso sobre a origem e os fundamentos da desigualdade entre os homens, é clara a denúncia contra os aguilhões, a subserviência dos fracos e a impostura dos poderosos. Entretanto, a quem se dedica aos estudos da condição feminina pode parecer estranho o fato de que Rousseau não tenha condenado a desigualdade de gênero, nem criticado os infortúnios da mulher em sua condição de secundariedade social e política. Embora o filósofo 
tenha comentado o tema, mesmo assim não parece ter sido uma de suas grandes preocupações e seus escritos acabam reproduzindo a visão da família patriarcal ${ }^{2}$ e o papel de passividade da mulher, ainda um pouco expressivos na sociedade do século XVIII, malgrado sua importância nesse contexto. ${ }^{3}$

Mesmo assim, Kelly e Grace (2009) afirmam que talvez dentre os grandes filósofos políticos Rousseau tenha sido quem mais deu atenção às questões relacionadas à mulher; e L'Aminot (1995) comenta que por bem ou por mal, Rousseau foi o filósofo que mais contribuiu com o movimento feminista dos séculos XIX e XX. ${ }^{4}$ Diante disso, o presente texto procura discutir a complexa problemática que aparece na obra do genebrino sobre o tema, parametrizando-o com as críticas formuladas pela filósofa inglesa Mary Wollstonecraft (17591797). Complexa porque, como ressaltam Kelly e Grace, Rousseau não deixou de abordar a questão, porém o fez de forma poética e ambígua, como muitos outros de seu tempo, seguindo a tendência literária dos philosophes, e não expressou de forma evidente sua visão sobre o problema. Exemplificando essa ambiguidade, por um lado Rousseau deixa claro que a política real deve ser papel do homem, restando apenas o comportamento virtuoso para as mulheres. Por outro, fica subtendido nos seus escritos que a mulher acaba revertendo a situação e protagonizando o cenário, se consideramos que é Sofia quem governa o Emílio ou Julie a real governanta da Comunidade de Clarens. Além do mais, não podemos esquecer o fato de o autor ter elogiado o papel das mulheres nas conquistas de Esparta e Roma, como o trecho que aparece logo no início do Emílio, sobre a mulher que louvara a vitória, mesmo tendo seus cinco filhos mortos na batalha. "Eis a cidadã", diz Rousseau (1973, p. 13) enfaticamente.

Os expoentes das luzes do século XVIII, na maioria, não escaparam de reproduzir em seus escritos a visão da família patriarcal e o papel de passividade da mulher, negando-lhe a mesma educação projetada para o homem e deixando-as na escuridão intelectual. Até porque, como diz Badinter (2003, p. 68), "do século XVII até o fim do século XIX, a mulher erudita é constantemente ridicularizada e tudo se faz para que ela não exista". Confirmando o que afirmara Fénelon, ainda no século XVII (1909, p. 144), que a mulher deveria se aplicar a "orar a Deus (...), a se tornar pobre de espírito (...) e a se calar, deixando os outros falarem". Perspectiva que adentrou o século seguinte e pode ser encontrada em maior ou menor grau também nos escritos de Diderot, do Barão de D’Holbach, de A. L. Thomas, e até de algumas mulheres, como Madame de Genlis, Madame de Maintenon, e a Marquesa de Lambert; além da já conhecida produção masculina inglesa nos nomes de Hume, Smith e Burke. Não foi diferente com a obra de Rousseau, a qual reproduziu essa compreensão geral da sociedade de 
seu tempo. Compreensão esta que teve poucas vozes em contrário, dentre elas a da filósofa inglesa Mary Wollstonecraft.

O nome de Wollstonecraft surge como contraponto a essa perspectiva, e seus escritos, juntamente com a produção intelectual de mulheres como Mme. D’Epinay e Mme. du Châtelet, podem ser considerados como as vozes com as quais o estatuto da mulher começa a ganhar mais visibilidade, saindo da sombra na qual se encontrava. Além, é claro, de Olympe de Gouges (1791), em sua Declaração dos direitos da mulher, quando diz logo no primeiro artigo: "A mulher nasce livre e permanece igual ao homem em direitos". Enquanto M. D’Epinay foi próxima de Rousseau e compartilhava com ele muitas de suas ideias, e Olympe Gouges ${ }^{5}$ tenha considerado o filósofo como um "amigo das mulheres" (OZOUF, 1997, p. 240), a filósofa inglesa, embora reconhecendo a genialidade de Rousseau, foi mais radical em sua crítica e em quase todas as obras o nome do filósofo aparece como referência de alguém que tenha pensado somente na educação do homem, negligenciando totalmente a educação da mulher, assim como seu papel político na sociedade. Ou, quando o fez, contribuiu apenas para piorar a situação, como afirma a autora: "Todos os escritores que escreveram sobre o tema da educação e as maneiras das mulheres, de Rousseau ao Dr. Gregory, contribuíram para fazer delas mais artificiais, de caráter fraco e, consequentemente, os mais inúteis membros da sociedade" (WOLLSTONECRAFT, 1996, p. 21).

Na obra $A$ vindication of the rights of woman (Reinvindicação dos direitos da mulher), Wollstonecraft interpreta que a educação apresentada no Emílio é um plano específico para o homem, e não para a mulher - a qual deve passar por apenas um treino a fim de que seja agradável aos homens ${ }^{6}$. Para ela, o que podemos chamar de "mundo de Sofia" é voltado a apetecer o homem e a fazer da mulher um objeto sujeito à vontade dele. Crítica que também vamos encontrar, embora em menor grau, na obra Les conversations de l'Emilie, escrito por Madame D’Epinay em forma de diálogo peripatético entre uma garota e sua mãe. ${ }^{7}$ No final da vigésima conversação a mãe afirma que poderá ser censurada por defender uma educação literária a uma menina, e receber conselho diferente, como este dado pelo censor: "sua filha bordará como um anjo, trabalhará como fadas, segundo todas as camareiras, cuja aprovação colocará o selo da imortalidade em sua reputação". E responde logo em seguida a sua filha: "Você não ficará mal-educada e ignorante" (1781, Tomo 2, p. 455).

Para ambas as autoras, enquanto a figura de Emílio simbolizaria as luzes, Sofia estaria nas trevas do conhecimento, da virtude e da cidadania. Contra essa crítica, interpreto que, por um lado, as circunstâncias da personagem Sofia, criada por Rousseau para ser a companheira de Emílio, o protagonista da obra, não poderiam ser restritas a uma condição de "trevas", como 
foi criticado por Wollstonecraft, porque, ao descrevê-la, Rousseau afirma: "Sofia está instruída dos deveres e direitos de seu sexo e do nosso. Conhece os defeitos dos homens e os vícios das mulheres; conhece também as qualidades, as virtudes contrárias, e tem-nas marcadas no fundo de seu coração" (ROUSSEAU, 1973, p. 467). Essa e outras passagens que comentarei depois demonstram que ela teve uma boa instrução doméstica, inclusive elevada para o padrão da época, além do auxílio do esposo em sua formação cultural. Não se trata apenas de conhecer o seu lugar, mas conhecer os defeitos, os vícios e as qualidades dos homens e das mulheres, isto é, capaz de fazer uma análise moral dos outros. Sua condição não era definitivamente de trevas, embora não estivesse no mesmo patamar intelectual ou social que Emílio, pois a proposta do tratado elaborado por Rousseau era a educação de seu protagonista e não a da companheira, escolhida somente quase no final da obra, como uma figurante que já havia tão somente recebido a educação burguesa de seu tempo. Como afirma Larrère (2012, p. 92) "a situação de Sofia é diferente", pois como mulher, sujeita a uma condição de dependência, sua educação se desenvolve por meio da razão prática e não pela razão sensível, como ocorre com Emílio. Ora, não era outra a condição de grande parte das mulheres desse século.

\section{A condição da mulher na França do século XVIII}

É notório que a condição da mulher nos oitocentos não era favorável a grandes sonhos ou empreendimentos. Pois, como relatam os irmãos Edmond et Jules de Gouncourt (1862), no livro La femme au dix-huitième siècle, quando nascia uma mulher a família não a recebia com alegria e festa, mas com decepção. Essa perspectiva que eles chamam de "costume e consciência" (p. 14) moldou as relações familiares e, consequentemente, a educação desse século, a ponto de não permitir ou dificultar a mobilidade social e a realização da "ambição feminina" (BADINTER, 2003) - uma vez que essa paixão era permitida a poucos, isto é, aos homens ricos e de certo destaque social, salvo raras exceções. Às mulheres sobravam os papeis de esposa, mãe e dona de casa, considerados os atributos essenciais de sua condição. A exceção cabia às mulheres de elite, as quais, segundo Goodman (2009), tiveram o escape da escrita de cartas, da literatura e dos salões. Perspectiva que se manteve no século seguinte ${ }^{8}$ e até mesmo no início do XX, como atesta Gina Lombroso, ao escrever na década de 20, afirmando: “a verdade é que as mulheres não se interessam pela política, principalmente as mulheres de família, muito ocupadas e preocupadas em distrair suas crianças” (LOMBROSO, 1929, p. 73).

Embora existissem mulheres educadas pelas famílias nobres no rigor do conhecimento acadêmico, como argumenta Goodman (2009), os campos das letras e das artes eram, por assim dizer, dominado pelos homens. A Enciclopédia (DIDEROT, 2015, p. 118 - vol. 5), por exemplo, 
a grande obra intelectual do século XVIII, tem autoria apenas masculina, sem a contribuição direta das mulheres do círculo cultural do qual os autores participavam, como a Madame d'Epinay, ${ }^{9}$ a Comtesse de Boufflers, ${ }^{10}$ a Mlle. Quinault ${ }^{11}$ e a Madame du Châtelet que era uma mulher dada às ciências, para citar apenas alguns nomes que tinham presença marcante nos salões e nos saraus parisienses, quando não eram elas mesmas as donas do espaço em que os intelectuais se reuniam para saraus, debates e jogos ${ }^{12}$. No entanto, seu poder se limitava às influências que exerciam sobre os frequentadores de seu espaço, e não em acesso ao poder e à ação política de fato. Casos como a da Madame de Pompadour, ${ }^{13}$ eram bem raros.

Além disso, mesmo que os autores da Enciclopédia tenham dado grande contribuição para a libertação do homem das amarras da Igreja e da Coroa, pois eram em grande parte republicanos, materialistas e humanistas, não fizeram muito esforço pela emancipação das mulheres. Nem mesmo Voltaire, dotado de espírito crítico e libertino, ousou escrever o suficiente no verbete "mulher" em seu Dicionário filosófico, a não ser alguns comentários sobre as diferenças físicas, além de críticas contra Montesquieu e a poligamia, sem, contudo, tomar uma posição clara em defesa da mulher.

No ambiente dos philosphes esse parecia ser um tema que os mesmos evitavam enfrentar e deixar sua opinião bem clara. Por exemplo, no verbete [mulher] da Enciclopédia, o longo e prolixo texto escrito pelo dramaturgo Desmahis ${ }^{14}$ exalta a beleza da mulher, sua ternura e a superioridade de seus encantos, mas limita-se a comentar as desventuras de algumas figuras femininas da literatura, para encerrar com uma visão tradicional de mulher-mãe, consagrada às virtudes domésticas. O texto traduzia a concepção geral que se tinha da mulher, incluindo a perspectiva dos philosophes, caso contrário não teria sido aceito entre os verbetes dessa obra. Outros, porém, chegaram a criticar a condição da mulher-objeto, como o fez Diderot na obra Sur les femmes, na qual chega a afirmar que se fosse legislador faria tudo para compensar seus males e, assim, retirá-las de sua escravidão (DIDEROT, 1919); além do polêmico texto ${ }^{15}$ do jovem Antoine Léonard Thomas, apresentado na Academia em 1771, e criticado pelo próprio Diderot e pela Mme. D’Epinay. ${ }^{16}$ Mas o número desses era insignificante, e quase todos, como o de Diderot, limitavam-se a lampejos críticos, comentários fugazes e declarações bem intencionadas, sem, contudo, constituírem-se em um tratado sistemático de defesa da mulher o que se configura somente no período pós-revolucionário, com a Declaration, de Olympe de Gouges, publicada em 1791. Thomas chegou a criticar a "escravidão doméstica da mulher" (1991, p. 61), mas afirmou que as mulheres eram incapazes de sentimentos universais e tinham menos sentimentos de justiça. No fundo, parece que todos concordavam com John Gregory (1724-1773), o qual escreveu um pequeno texto orientando suas filhas (A father's legacy to his 
daughters $)^{17}$ a serem amáveis, piedosas, humildes e a possuir todas as virtudes a fim de arrumar um bom casamento.

Por isso é preciso discordar de Damrosch (2007) o qual afirma na introdução de sua obra (Jean-Jacques Rousseau: restless genius) que Rousseau endossou uma visão de subserviência feminina que já estava ultrapassada no seu tempo. Em primeiro lugar, não vejo esse endosso tão claro assim; em segundo, um exemplo de que essa visão não estava ultrapassada é o fato de o livro do Dr. Gregory ter sido uma das obras mais populares do século XVIII, com bastante sucesso ainda no século XIX, tanto na Inglaterra como na França, bem como por toda a Europa. Outra obra de sucesso foi o De l'éducation des filles, de Fénelon, que também defendia a preparação educacional feminina para fins matrimoniais. Como afirma Badinter (2003, p. 370), "De Fénelon ${ }^{18}$ a Madame de Genlis, passando por Madame de Maintenon, à Marquesa de Lambert e Rousseau, os pedagogos perseguiram uma mesma finalidade: formar as meninas para serem futuras esposas, mães e donas-de-casa". Ideia que sofreu poucos ataques, a ponto de em pleno Século XX, Lombroso (1929) defender, em $A$ mulher na sociedade atual, que as atividades políticas não seriam convenientes à mulher, a qual deveria dedicar-se ao cuidado da família, repetindo uma ideia comum no século XVIII de que o homem deve "reinar" na cena pública e a "mulher" reinar na cena privada - tal como aparece no Emílio.

$\mathrm{O}$ ataque mais significativo, e panfletário, contra esse cenário, veio de fora do mundo parisiense ou do grupo dos iluministas, ou seja, da filósofa inglesa Mary Wollstonecraft, a precursora do feminismo que condenou o livreto do Dr. Gregory e indignou-se com os escritos de Rousseau. A "avó de Frenkenstein"19 criticou o iluminismo francês por seu paradoxo de defender a igualdade e, ao mesmo tempo, testemunhar passivamente a desigualdade entre os gêneros, tal como, segundo ela, o fez Rousseau. Não há registros se houve uma interação entre Rousseau e a filósofa inglesa, mas certamente que sua crítica talvez tenha agravado a síndrome de perseguição que Rousseau alimentava, sobretudo quando residiu na Inglaterra e se desentendeu com David Hume (1711-1776); em seus últimos dias de vida. Mais do que isso, o tema ganhou uma repercussão que até hoje o discutimos e passou a figurar no trabalho das feministas. Tanto que Lynda Lange ao organizar o livro Feminist interpretations of JeanJacques Rousseau (2002) diz na introdução que o "pior pesadelo de Rousseau" é ter um grupo de mulheres acadêmicas discutindo sua obra. E eu acrescento: sobretudo quando a discussão toma um caráter estritamente condenatório, sem se dar o trabalho de analisar a obra rousseauniana em suas especificidades e contextualizações. 
Tomando um exemplo, a corrente mais radical, da metade do século XX em diante, condena Rousseau por seu suposto anti-feminismo (L'AMINOT, 1995), mas não compara com todos os textos de outros pensadores, os quais cito aqui, e deixa de lado o protagonismo da mulher que pode ser prospectado na personagem Júlia, a qual goza de um certo poder político em seu mundo, a comunidade de Clarens. Se o mesmo não ocorre com Sofia é porque seu mundo não entra no mesmo universo pedagógico e metodológico dos outros dois personagens: Júlia e Emílio. É o que o texto procura discutir abaixo.

\section{O mundo de Sofia}

Considerando, assim, que o romance Júlia ou a Nova Heloisa concede mais protagonismo à mulher, a ponto de ser Júlia uma espécie de "primeiro-ministro" da comunidade de Clarens e quase uma "sacerdotisa" do jardim que edificara, no Emílio encontramos uma mulher diferente, que nem gosta de atividades na terra, como trabalhar no jardim. Embora seja relativamente "bem-nascida e de um temperamento naturalmente bom" (ROUSSEAU, 1973, p. 462), além de virtuosa, pois "ama a virtude" (ROUSSEAU, 1973, p. 466), Sofia não goza do mesmo protagonismo que Júlia. Além de ficar à sombra de Emílio, tudo deve fazer para agradálo. Assim, ao secundarizar seu papel no matrimônio, ${ }^{20}$ Rousseau acaba projetando, segundo Wollstonecraft (1996), uma educação da mulher para o simples conformismo e para que seja o "membro mais inútil da sociedade" (WOLLSTONECRAFT, 1996, p. 21). Pois, como ela afirma:

Rousseau declara que a mulher nunca deveria, por nenhum momento, sentir-se independente, mas que deveria ser governada pelo medo de exercer sua astúcia natural e fazer dela uma escrava a fim de torná-la um objeto de desejo mais atraente, uma companheira mais doce para o homem, sempre que ele decidir relaxar-se (WOLLSTONECRAFT, 1996, p. 25).

À primeira vista, o que nos parece, no Emílio, é que a realidade de Sofia não passa mesmo disso, ou seja, de um mundo de mera submissão e compromisso às obrigações familiares; e a educação projetada por Rousseau faz dela a dócil companheira sem nenhum papel social. Embora possa ter ideias, dar opiniões e contribuir com a administração do lar, deve ser educada desde cedo a obedecer e a sofrer injustiças. Segue-se ainda que Sofia deve saber cantar, dançar e conversar animadamente, sem se preocupar com as questões de metafísica e teologia: "A arte de pensar não é estranha às mulheres, mas elas não devem interessar-se senão ligeiramente pelas ciências de raciocínio. Sofia tudo concebe, mas retém pouca coisa” (ROUSSEAU, 1973, p. 502). 
Porém, o que se descortina no Livro V é o que Piau-Gillot (1981, p. 391) chama de “catálogo das características do eterno feminino: timidez, modéstia, pudor", como substrato da mentalidade social desse tempo. Além do mais, a ideia da mulher como propriedade e domínio - e muitas vezes fazendo comparação com a posse da terra - era comum no século XVIII. Mesmo assim, ao desposar Sofia, Emílio não iria simplesmente "amanhar", "semear" e cuidar de sua propriedade, tal como foi ensinado a fazer quando era criança e recebera um pedaço de terra para lavrar, em forma de acordo contratual com o dono da terra. ${ }^{21}$ Enquanto o Sr. de Wolmar pode ser considerado o proprietário legal de Júlia, haja vista o contrato matrimonial estabelecido; e Saint-Preux o possuidor, por ser seu amante e possuir sua alma, no Emílio amante e esposo são a mesma pessoa. Por isso Rousseau prefere usar o termo "companheira", logo no início do livro V, a qual precisava "de um amante" (p. 475). O que reverbera o plano platônico (A República) do bom filho, do bom pai, da boa mãe e do bom marido na constituição do Estado. Por isso e pelos elogios que Rousseau faz às mulheres espartanas e romanas, são equivocadas as observações de Wollstonecraft sobre o "barbarismo" na teoria política de Rousseau; bem como a observação de Badinter (In: THOMAS; DIDEROT; D`EPINAY, 1991) de que a mulher rousseauniana é tola e inculta.

É possível verificar, pelo relato do Emílio, que Sofia teve uma das melhores educações de seu tempo, a qual a capacitou para ajudar a governar a casa de seus pais. Criada "como tesouro" (p. 482) por eles, em forma de educação doméstica, essa "aluna da natureza" (p. 482) aprendeu de imediato a ser modesta, bem-comportada e até requintada ao seu modo, além de ter desenvolvido os talentos naturais, como o canto. Bem orientada pela família, Sofia foi levada, contra o costume, a escolher o próprio esposo - o que não era comum na época, vale ressaltar. E, assim, tendo escolhido e sido escolhida "por concordância dos corações" (p. 493), Sofia contraiu matrimônio e ganhou alguém que a ajudou a completar sua formação, como nos relata Jean-Jacques, o preceptor (p. 501-2): “Sofia gosta de cantar, ele [Emílio] canta com ela (...) ensina música (...) dança com ela (...) afina o cravo para ela (...), dá lição de filosofia, de física, de matemática, de história, de joelhos diante dela, passeia a cavalo com ela para ver as belezas do campo, acompanha-a em seus passeios à pé pelas campinas". Como chamar essa mulher de "tola" e "inútil”, se ela estudo filosofia, matemática e física? É certamente um anacronismo e uma interpretação equivocada - ou de má-vontade - dos escritos do genebrino. Piau-Gillot (1981, p. 322) questiona: “O modelo ontológico proposto por Rousseau é consistente com o da ideologia dominante. Ele obviamente não é progressista, mas podemos considerá-lo como anti-feminista?” Creio que não. 
$\mathrm{Na}$ fala do preceptor aparecem, portanto, essas nuances da ideologia dominante, como considerar a mulher mais propensa ao desregramento das paixões. Percebendo, por exemplo, que Emílio acaba tornando-se um "escravo" do amor-próprio de Sofia, de seus caprichos e desejos, o preceptor resolve separá-los por um período de tempo, explorando, bem antes que a romancista inglesa Jane Austen em sua obra Razão e Sensibilidade, os perigos de um relacionamento atraído apenas pela paixão. E para evitar o desenfreamento dessa paixão, alimentando o amor-próprio, Rousseau prevê uma fenomenologia da memória que se diferencia da imaginação e da representação criativa. Tomando aqui a perspectiva de Paul Ricoeur (2007), o que há no Emílio é um exercício mnemônico, isto é, da mneme e não da anamnesis. Ou seja, enquanto que a anamnesis é entendia como um esforço, uma prática da memória para relembrar algo, a mneme é uma lembrança-afeto, algo que vem da alma, espontaneamente, causando nostalgia (saudade). Emílio passará por um processo de desenvolvimento da admiração, admirando o presente pela observação sensual do que vê, em suas viagens, e o ausente pela memória de sua amada. Algo que nos remete ao Teeteto, de Platão, que coloca a admiração como origem da filosofia. ${ }^{22}$ Para se evitar os opostos extremos entre a cópia perfeita, o eikon (que poderia ser uma foto de Sofia) e o phantasma, ou seja, o simulacro ou cópia defeituosa, Emílio precisa exercer sua capacidade de reviver os doces momentos que experimentou nos dias de namoro e as virtudes da amada, agora em sua ausência. Memória e admiração são aguçadas com as viagens. Portanto, o sentido de "escala" (p. 542) que é empregado para as medidas das leis políticas das regiões visitadas, deverá tornar-se um instrumento de medida também dos sentimentos.

Não é à toa que o preceptor faz Emílio ler Telêmaco, livro que contém a história do filho de Odisseu que passa os dias buscando na memória a figura de seu pai que partiu de Ítaca para a guerra. Sofia também leu a obra e deve estar, no contexto da narrativa, como o jovem, contando os dias para a volta de seu herói. O final do livro Emílio é bastante conhecido: o casal se une em matrimônio e recebe os conselhos para sua felicidade. Um deles deve ter provocado a ira de Wollstonecraft e de outras mulheres: "Tornando-se vosso marido, Emílio tornou-se vosso chefe; cabe-vos obedecer, assim o quis a natureza" (p. 567), diz o preceptor encerrando sua obra. Se não há aqui um avanço do papel da mulher na sociedade é porque, repito, Sofia representa a mulher e a instrução de seu tempo. Ademais, se Rousseau não concede um papel político nem ao Emílio, como o concederia a Sofia?

E para quem conhece a obra Emílio e Sofia ou os solitários, sabe que não viveram felizes para sempre. Talvez a morte de seus pais e a da filha tenha provocado em Sofia a desilusão da vida, levando-a à indiferença. Em busca de preencher o vazio, convenceu Emílio a mudar-se 
para a cidade (Paris), contrariando o conselho de Jean-Jacques e a vontade de seu esposo. O que veio a seguir foi desentendimentos, traição e separação, levando seu mundo a um desfecho bem diferente do fim virtuoso de Júlia. Nada disso, entretanto foi suficiente para uma leitura menos drástica da obra de Rousseau, feita pela filósofa inglesa Mary Wollstonecraft.

\section{As críticas de Mary Wollstonecraft}

Mary Wollstonecraft foi escritora e filósofa, conhecida defensora dos direitos das mulheres. Como estudiosa da Revolução Francesa, centrou sua leitura nos nomes que direta ou indiretamente influenciaram o movimento. A influência do iluminismo sobre seu pensamento não a impediu de tecer críticas contundentes sobre as posições de Diderot, as quais considerou ainda paternalistas; contra a obra de John Gregory, em seu A father's legacy to his daughters, cujo conteúdo está cheio de conselhos para fazer as mulheres amáveis; e, por fim, voltou-se também contra Rousseau, cujo nome aparece ao longa da obra $A$ vindication of the rights of woman, na qual defende que não há diferença entre o homem e a mulher, a não ser na forma como são educados - opinião compartilhada por Madame d'Epinay (1781), para quem a mulher é um ser de cultura inteiramente moldado pela educação.

Embora a perspectiva rousseauniana não possa fugir muito da crítica feita por Wollstonecraft, em minha opinião houve uma leitura apressada e panfletária do pensamento de Rousseau por parte da filósofa e que malgrado a visão tradicional própria do século XVIII, qual seja a de sujeição da mulher, a da educação para os trabalhos domésticos etc. presente nos escritos de Rousseau, alguns trechos do Emílio e até de outras obras, como a Júlia ou a Nova Heloísa, podem lançar novas luzes e revelar um filósofo que de alguma foma se diferenciou da tendência geral deu seu tempo e que só não militou a causa - tal como o fez Wollstonecraft porque sua filosofia é a da condição humana e seu plano de formação é para o "homem" no sentido de ser humano.

Mesmo assim, não ficou fácil sustentar tal leitura após a publicação e a divulgação dos escritos de Wollstonecraft. Ou seja, ficou complicado defender Rousseau na questão aqui anunciada, pois à primeira vista o que nos parece em seu ponto de vista é que indubitavelmente a condição da mulher é de total sujeição ao homem, restrição ao ambiente doméstico e nenhuma participação político-social. Principalmente quando nos deparamos com passagens em sua obra maior de formação humana, o Emílio, que deixam claro que a educação do jovem está voltada para que ele seja mestre de si mesmo, independente e dono de seu destino; enquanto que Sofia, a esposa, parece destinada a uma vida de submissão, frivolidades e aparência. Há trechos nos quais Rousseau tece comentários sobre a educação de Sofia e chega a dizer que ela deve "gozar 
de pouca liberdade" (ROUSSEAU, 1973, p. 430) e que as mulheres "sejam modestas e saibam cuidar do lar" (p. 434).

Entretanto, ao mesmo tempo que nos deparamos com trechos que poderíamos chamar de machistas, encontramos outros que podem significar o contrário, como o que se segue:

\begin{abstract}
A relação social dos sexos é admirável. Dessa sociedade resulta uma pessoa moral de que a mulher é o olho e o homem o braço, mas com tal dependência um do outro, que é com o homem que a mulher aprende o que é preciso ver, e com a mulher que o homem aprende o que é preciso fazer. Se a mulher pudesse remontar tanto quanto ela o espírito dos pormenores, sempre independentes um do outro, viveriam numa eterna discórdia e sua associação não poderia subsistir. Mas na harmonia que reina entre ambos tudo tende a um fim comum; não se sabe quem mais se dedica; cada qual segue o impulso do outro; cada qual obedece e ambos são senhores (ROUSSEAU, 1973, p. 439).
\end{abstract}

Quanto a Wollstonecraft, seu trajeto de vida teve início no proletariado inglês quando, filha e neta de tecelões, conseguiu estudar um pouco e abrir, com sua irmã, uma escola no norte de Londres. A filósofa acompanhou de perto as transformações na França e em 1790 publicou seu primeiro panfleto: A vindication of rights of men (Reinvindicação dos direitos do homem), escrito em forma de carta-resposta ao filósofo Edmund Burke (1729-1797), criticando suas posições políticas. Nele, o nome de Rousseau aparece pouco porque ela se limita a refutar a crítica de Burke à Revolução Francesa. ${ }^{23}$

É no $A$ vindication of the rights of woman que o nome do filósofo genebrino aparece com maior frequência. Embora sempre o admirasse de forma respeitosa, e o chamasse de "gênio" (WOLLSTONECRAFT, 1996, p. 24), como um escritor que possuía uma "caneta mágica" (p. 13) ${ }^{24}$, a autora afirma que a mulher rousseauniana é sujeita de uma educação deficiente, cujo objetivo principal é fazê-la submissa, um "insignificante objeto de desejo" (p. 9), que cai facilmente no regime de opressão. Escrito em resposta ao documento apresentado à Assembleia Constituinte de 1791, por Talleyrand ${ }^{25}$ - que não mencionara a educação da mulher -, o texto da filósofa inglesa pode ser considerado um amadurecimento e uma ampliação das ideias defendidas nas obras anteriores. Por exemplo, no texto de 1787 (Thoughts on the education of daughters) a autora concorda com Rousseau no que diz respeito ao papel da mulher na condução do lar, como mãe e esposa. Aliás, segundo ela (WOLLSTONECRAFT, 1787, p. 58), a preparação da mulher para exercer bem esses papeis deve ser uma das principais preocupações tanto da educação pública quanto doméstica durante os primeiros anos de vida das moças. Até porque, como a maioria das mulheres sem dote não conseguiam bons casamentos, a boa educação poderia ser compensadora. Perspectiva que foi bastante ampliada no texto de 1792 ( $A$ vindication of the rights of woman) no qual aparece a defesa de uma 
educação contra o acondicionamento doméstico da mulher. Pois, segunda ela, a felicidade depende não apenas da virtude, mas da razão e do conhecimento - ambas negadas, segndo ela, pela perspectiva educadora tanto do Dr. Gregory quanto de Rousseau.

Seguem de forma comentada e sintetizada (sem nenhuma hierarquia) os principais pontos que Wollstonecraft considerou problemáticos no pensamento do genebrino:

\section{1) Fins da educação}

Para a filósofa inglesa, a finalidade maior da educação não é a reconciliação entre natureza e cultura pelo desenvolvimento da sensibilidade, como se pode depreender do pensamento de Rousseau, mas desenvolver a capacidade de regular as paixões (constituintes da natureza humana) pelo cultivo da razão ${ }^{26}$. Como ela afirma no início do $A$ vindication.... “o aperfeiçoamento de nossa natureza e da capacidade de ser feliz deve ser avaliada pelo grau de razão, virtude e conhecimento" (WOLLSTONECRAFT, 1996a, p. 11). E, para isso, é preciso: "regular as paixões assim que elas começam a se fermentar" (p. 20), até porque "as paixões são auxiliares necessários à razão" (p. 28).

\section{2) Desigualdades}

Ela concorda com Rousseau quanto às desigualdades naturais e quanto à fragilidade física da mulher: "No governo do mundo físico, é observável que a mulher é geralmente inferior ao homem, em termos de força" (WOLLSTONECRAFT, 1996a, p. 7). O problema é que isso foi utilizado como argumento de defesa da superioridade masculina e seu domínio na vida social, transformando as mulheres em "insignificantes objetos de desejo" (p. 9). Ao defender o estado de natureza, Rousseau, segundo ela, endossa essa perspectiva e condena a única forma de corrigir o problema da diferença, ou seja, pelo processo civilizatório.

\section{3) Progresso}

O desenvolvimento social pode, contrariamente ao que anunciou Rousseau, possibilitar o progresso da sensibilidade e do entendimento, conduzindo os homens à perfeição, bem longe do estado de ignorância. Ela chega a dizer que:

A natureza do veneno contém seu antídoto. E se Rousseau tivesse subido um degrau em sua investigação, ou seus olhos tivessem visto melhor através da névoa na qual recusou respirar, sua mente ativa poderia ter compreendido que a perfeição do homem ocorre na civilização (WOLLSTONECRAFT, 1996a, p. 17). 
O que considero um equívoco de leitura, pois, baseado em Starobinski (2001), ${ }^{27}$ Paiva (2016, p. 434) afirma que a crítica rousseauniana da cultura não está alheia ao fato de que "o mal contém seu remédio na medida em que for utilizado para evitar um mal pior, como um antídoto em benefício público". Ou seja, numa análise cuidadosa é possível verificar mais aproximação do que distanciamento entre Rosseau e Wollstonecraft neste tema.

\section{4) Vida doméstica}

Fora as diferenças naturais, a única diferença entre homem e mulher está na forma em que são educados. Wollstonecraft (1996a) adverte que a educação de seu tempo era primaz em fazer das mulheres “objetos insignificantes de desejo" (p. 9). Para ela, Rousseau contribui com essa visão ao afirmar que a mulher não deve ser independente, mas deve permanecer uma "doce companhia" (p. 25) do homem, exercendo suas virtudes na vida doméstica - o que, segundo ela, levou fatalmente a vida doméstica à condição de opressão, negando à mulher sua liberdade. Diz ela (1996a, p. 36): “A liberdade é a mãe da virtude e se as mulheres, em seu modo de ser, tornaram-se escravas, sem poder respirar o vigoroso ar da liberdade, serão exibidas apenas como seres exóticos e, reconhecidamente, relegadas como bonitas falhas da natureza". Ou seja, para ela, a boa educação que uma mãe pode dar à filha é diametricamente oposta ao plano recomendado por Rousseau em seus "eloquentes sofismas” (p. 40). E, em mais um equívoco, ela toma a educação de Sofia como o plano de Rousseau para a educação da mulher e diz: "O que eu ataco são os princípios nos quais sua educação foi construída” (p. 24).

\section{5) Modéstia}

Para Wollstonecraft (1996a, p. 128), tanto Rousseau quanto o Dr. Gregory defendem a modéstia como forma de renúncia e devoção incondicional ao amor, tal como fez Júlia. A modéstia é, invariavelmente, humilhante por operar uma sujeição da mulher sob o pretexto do amor e da paixão: “o negócio de suas vidas é a galanteria - elas são ensinadas a agradar e vivem apenas para agradar" (p. 23). Para ela, (p. 129) a modéstia deveria ser igualmente cultivada por ambos os sexos, e ambos deveriam se amar de forma igual (p. 30), de modo que a mulher possa, ao final, tornar-se uma amiga do esposo e não alguém que viva sob sua dependência (p. 28).

\section{6) Reputação}

A autora concorda com Rousseau de que uma formação virtuosa não pode prescindir da moralidade. Ela reconhece que havia mulheres depravadas, principalmente em Paris; e que mulheres foram déspotas ao longo da história. Mas discorda do genebrino quando, segundo ela, 
o mesmo foca na reputação e na castidade como a principal tarefa da mulher (WOLLSTONECRAFT, 1996a, p. 137). Ou seja, todo o luxo, a pompa e o progresso da razão contribuiu, como afirma Rousseau, para a depravação dos costumes, em geral, com efeitos em ambos os sexos. Por que, segundo ela (p. 149) cobrar somente da mulher a reputação e a finesse?

A visão de Rousseau é, certamente, conservadora, porque tem como foco a família e os papeis tradicionalmente separados. De modo que ele centra a responsabilidade da mulher dentro das duas esferas de confluência familiar: esposa e mãe. Entretanto, imputar-lhe uma perspectiva misógina é de um anacronismo grosseiro. Por isso, como diz Lange (2002), ainda em sua introdução, sem uma análise mais aprofundada, considerando o contexto de sua época e a contribuição que o mesmo possa ter dado ao debate, Rousseau poderia hoje facilmente ser chamado de machista e seria possível afirmar que seus escritos buscam fundamentar a exclusão das mulheres do mundo político, se tomarmos suas afirmações sobre o papel das mulheres na sociedade. Talvez a pior delas é a afirmação no Emílio (p. 466), de que "a mulher é feita para ceder ao homem e até para suportar a injustiça dele" - algo que pode nos repugnar hoje, mas que era comum na época e defendido pela Igreja, como forma de purificação da mulher.

Rousseau integra a filosofia política e moral de seu tempo a qual procurava explicar as origens e as razões das diferenças constituintes, buscando geralmente a causas na própria natureza: naturalmente homens e mulheres são diferentes. Rousseau reconhece essa diferença, tal como o fez Wollstonecraft, destacando que foi no estágio pré-social, quando da instituição da família, é que os papeis foram aos poucos sendo diferenciados. Porém, na base de seu pensamento, no Segundo discurso, por exemplo, a liberdade natural determina uma igualdade natural onde não há uma diferença significativa de gênero. A famosa frase da descrição do homem natural: "vejo-o fartando-se sobre o carvalho..." (ROUSSEAU, 1999, p. 58), bem poderia ser aplicada no feminino: "Vejo-a fartando sobre o carvalho...". O encontro furtivo, para satisfação sexual, não gerava nenhum vínculo, nem, tampouco, diferença, subjugação ou domínio: após a cópula, ambos seguem seus caminhos separados e independentes. Quando aparece a família, embora em forma de uma sociedade natural (vide nota 1), destaca-se o poder paterno pelo fato natural de ser fisicamente mais forte que sua esposa e sua prole.

No Emílio há um conjunto de preceitos e recomendações para vida doméstica. As mulheres são incentivadas a amamentarem seus filhos, a serem boas donas de casa e a amarem a seus maridos. Mas não creio que a condição da mulher aí seja só isso, uma vez que o autor abre o prefácio dizendo que a obra tinha sido iniciada para agradar a "uma boa mãe que sabe pensar" (grifo meu). Abre-se para ela, portanto, um espaço de influência e condução virtuosa até mesmo social, tal como podemos vislumbrar no caráter de outra personagem, a Nova 
Heloísa, sobre a comunidade de Clarens. Júlia e o Sr. de Wolmar são, por certo, diferentes na constituição física, no caráter e nas ideias. Mas há no romance uma espécie de igualdade na diferença, uma vez que partilham uma harmonia que também está prevista no Emílio. A diferença é que Júlia desenvolve um papel social relevante em sua comunidade.

Ou seja, nem Rousseau e nem Wollstonecraft condenaram a ideia de família e de responsabilidades distintas dentro dessa sociedade. Enquanto no pensamento da filósofa inglesa é possível prospectar uma ideia de "consentimento", quando ela diz que a mulher não pode pela força ser confinada aos deveres domésticos (1996a, p. 3), em Rousseau a vida pessoal e doméstica goza de uma certa importância social: "Ela deve reinar na casa como um ministro de Estado" (Emílio, p. 480). Perspectiva que consolida em Sofia somente seu reinado doméstico, mas que se amplia em Júlia a qual, além de protagonista do romance, é quem realmente administra sua comunidade. Se a mesma situação não é clara no Emílio, é questão lógica: Sofia não recebeu a mesma educação proporcionada pelo preceptor do jovem Emílio, nem tampouco por Saint-Preux, o preceptor de Júlia. Ela foi educada pela sociedade na perspectiva da educação francesa tradicional, criticada por Rousseau. É preciso lembrar que: "o que Sofia sabe mais a fundo, e que lhe fizeram aprender com mais cuidado, são os trabalhos de seu sexo" (Emílio, p. 473 - grifo meu). Se essa personagem tivesse triunfado na perspectiva da virtude e da sabedoria e com papel político, seria uma contradição e não apenas um paradoxo.

\section{Considerações Finais}

Como foi discutido, por um lado a obra de Rousseau reforça a visão tradicional da relação homem-mulher, herdada pela tradição vigente, de destinação da mulher à maternidade e à lógica da complementação do homem, tal como aparece e se desenvolve a figura de Sofia no livro V do Emílio. Dessa forma, concordando um pouco com Badinter (2003) é preciso dizer que Rousseau não inovou nada nesse ponto. Por outro lado, participava ativamente dos salões literários organizados pelas mulheres intelectuais de seu tempo, além de ter contribuído com a discussão em torno da educação da mulher, na figura da personagem Júlia. Além de produzir trechos poéticos, como este sobre o matrimônio:

Dessa sociedade resulta uma pessoa moral de que a mulher é o olho e o homem o braço, mas com tal dependência um do outro, que é com o homem que a mulher aprende o que é preciso ver, e com a mulher que o homem aprende o que é preciso fazer. Se a mulher pudesse remontar tanto quanto o homem aos princípios, e se o homem tivesse tanto quanto ela o espírito dos pormenores, sempre independentes um do outro, viveriam numa eterna discórdia e sua associação não poderia subsistir. Mas na harmonia que reina entre ambos tudo tende a um fim comum; não se sabe quem 
mais se dedica; cada qual segue o impulso do outro; cada qual obedece e ambos são senhores. (ROUSSEAU, 1973, p. 439).

Assim como Rousseau criticava os jardins franceses, a música francesa, criticava também a forma que os franceses tratavam suas mulheres. Talvez até concordasse com a análise ponderada de Mme. d'Epinay, quando diz: “a fraqueza de nossa constituição e de nossos órgãos pertence certamente à nossa educação, e é uma consequência da condição que nos destinaram na sociedade". "Certamente", continua ela, "seriam necessárias várias gerações para nos recolocar tais como a natureza nos criou" (THOMAS, 1991, p. 138), como estamos vivenciado agora. Posso estar "forçando a barra", mas vejo no Emílio uma crítica velada e sutil a esse tratamento e à educação feminina. Falando aos franceses, Rousseau disse no Emílio (1973, p. 458): "Infeliz o século em que as mulheres perdem sua ascendência e em que seus juízos não interessam mais os homens! É o último grau da depravação. Todos os povos que tiveram bons costumes respeitaram as mulheres". Não me parece a posição de um machista inveterado, um misógino, como alguns textos sugerem e algumas críticas tentam enquadrar o filósofo de Genebra. Além do mais, vale lembrar que embora vários textos elogiassem as virtudes femininas, como o texto de Thomas, segundo os relatos, ${ }^{28}$ as mulheres diziam que tais elogios as lisonjeavam menos do que as doces e apaixonadas injúrias de Rousseau. Ou seja, se Rousseau não foi inovador, pelo menos deu mais protagonismo à mulher em seus escritos do que nas obras de muitos de seus contemporâneos, como os nomes da produção já conhecida.

Diante de um quadro sócio-histórico no qual, segundo Edmond e Jules de Gouncourt (1862), a primeira educação dada a uma mulher não tendia a outra coisa a não ser corrigir sua vivacidade, controlar sua infância e seu movimento natural, além de reprimir seu caráter e seu corpo, a educação recebida por Júlia destoa bastante dessa acepção e vai muito além da aprendizagem do catecismo, da música (canto, dança e cravo) e das artes domésticas. Além disso, foi ela quem planejou, construiu e administrou o Eliseu, o exemplar jardim à moda inglesa. Segundo Keith Thomas (1988), o uso da metáfora do jardim tinha suas raízes na tradição clássica, mas com uma dimensão espiritual, religiosa - o que faz de Júlia uma sacerdotisa, alguém que com honestidade, talento, carisma e benevolência (o que se espera de qualquer sacerdote), pode exercer seu domínio. Como o próprio Rousseau afirma no Emílio (1973, p. 461):

mas a mulher a um tempo honesta, amável e circunspecta, a que força os seus a respeitá-la, a que tem reserva e modéstia, em uma palavra a que sustenta o amor pela estima, manda-os a um simples sinal ao fim do mundo, ao combate, à guerra, à morte em o querendo. Este império é belo, parece-me, e vale a pena adquiri-lo. ${ }^{29}$ 
Se Sofia não teve o mesmo percurso educativo de Julia é porque, vale repetir, enquanto esta representava o projeto rousseauniano de educação da mulher, a outra representava o sistema de educação doméstica da sociedade francesa de então, nos moldes de Fénelon e de Gregory e dos demais que se lançaram à tarefa de redigir tratados sobre o tema e por eles ficaram tão famosos. Certamente que, ao escrever as Conversações d'Emilie numa forma de contraposição à figura de Sofia, segundo Badinter (2003), Louise d'Épinay reproduz a mesma relação íntima encontrada entre o educador e o educando, no Emílio, resguardadas as diferenças, pela qual provoca na menina um grau de autonomia, responsabilidade e conhecimento não muito diferente do que ocorreu com a personagem rousseauniana da Nova Heloísa. Pois, como afirma Gréard (1889), Madame d'Épinay estava bastante impregnada da doutrina de Rousseau para fugir dela. Como poderia colocar-se como seu rival, se o próprio Rousseau lera e aprovara seu texto? ${ }^{30}$

Por fim, o que pretendo dizer é que entre a condição geral de secundaridade e submissão da mulher oitocentista, vivendo nas sombras do elemento masculino, e o status de iluminação que Wollstonecraft, de Gouges e Nísia Floresta ${ }^{31}$ advogavam, há uma escala na qual Sofia pode ser posicionada no meio termo, nem totalmente nas trevas, nem totalmente na luz, gozando de um status que a coloca à frente da maioria das mulheres de seu tempo, embora não tenha preeminência sobre o Emílio por ser este o personagem central do romance e a figura que representa a formação humana conforme Rousseau a concebia. De uma forma ou de outra a perspectiva rousseauniana fomentou o debate tanto na Europa quanto no Brasil, de modo que desde Nísia Floresta, Violeta Leme, Bertha Lutz, entre outras, até hoje estamos a debater o tema. E, concordando com Piau-Gillot (1981), a concepção sexista de Rousseau é superada por um plano maior de formação humana e por suas discussões sobre as mudanças no campo da moral e da política. Há tanto em Júlia quanto em Sofia uma dimensão natural e social que configura antropológica e axiologicamente a mulher no contexto do século XVIII, e não seu estatuto ontológico.

E como o próprio Rousseau nos adverte, em seu pequeno texto Ideé de la méthode dans la composition d'un livre, inserido na série Mélanges de littérature et de morale, das Oeuvres Complètes (T. II, p. 1247), “a última parte de uma obra pode ser empregada para comparar”, gostaria de fazer então uma comparação entre Emílio e Sofia, remetendo-me à advertência de Larrère (2012, p. 94) quando diz: "Sem dúvida que a Sofia não é uma mulher de conhecimento, mas Emílio não é um homem de ciência. A recusa do intelectualismo não pode ser aplicada somente à educação de Sofia”. Do mesmo modo se Sofia não tem papel político na sociedade, 
Emílio não é um cidadão. Ambos deixaram-se levar pelo desregramento do amor próprio, mas diferente de Sofia, Emílio manteve-se virtuoso mesmo na adversidade. O que era de se esperar, pois ela não fora educada tal como Emílio e, certamente, não pode ser tomada como modelo ou ideal rousseauniano de educação feminina. Seu ideal de educação da mulher está modelado no processo educacional de Saint-Preux, empregado com Júlia, ${ }^{32}$ e não no que se desenvolve com Sofia, no Emílio. Aliás, a corrupção moral de Sofia aponta para o fracasso de sua educação - o que permite uma interpretação de que nela não reside a defesa rousseauniana da educação da mulher, mas sua crítica. 


\section{Notas:}

${ }^{1}$ Professor da Faculdade de Educação da Universidade Federal de Goiás (UFG) e do Programa de Pós-Graduação em Educação (PPGE) da UFG (stricto sensu), Goiânia, Goiás, GO, Brasil. E-mail: wap@usp.br

${ }^{2}$ Rousseau afirma no Discurso sobre a economia política, ao comentar a saída do estado de natureza, que ocorreu por diversas razões, que: "o pai deve comandar a família" (ROUSSEAU, 1964, T. III, p. 242). Mesmo assim, segundo Derathé $(2009$, p. 281), "ele não funda o poder paterno sobre um contrato, distanciando-se assim da teoria admitida na escola do direito natural. Para Rousseau, a família não é um estabelecimento humano instituído por meio de um pacto, mas é uma sociedade natural".

${ }^{3}$ Embora seja importante ressaltar que a atuação feminina no meio intelectual durante todo o século XVIII foi significativa para romper com essa visão. Vide a obra The Eighteenth-century woman, de Olivier Bernier (1981) que dá destaque à Mme. de Pompadour, ou outras obras que trazem a contribuição, por exemplo, de Gabrielle Émilie Le Tonnelier de Breteuil, marquesa de Châtelet-Laumont (1706-1749), a escritora e cientista que traduziu para o francês a obra de Isaac Newton (1643-1727) Princípios Matemáticos da Filosofia Natural. Influenciou Voltaire com o qual teve um relacionamento intelectual e amoroso.

${ }^{4}$ L'Aminot (1995, p. 153) informa que: “A crítica feminista de Rousseau durante o período que o movimento é organizado, que vai de 1880 a 1918, é bastante variada. (...) Longe de o condenar por essa opinião [de que seu tratado de educação subordina a mulher ao homem], as feministas do começo do século são indulgentes para com ele. Para grande parte delas, Rousseau ainda conserva seu poder revolucionário e suas ideias não são tidas como como um risco às conquistas da mulher moderna, como serão interpretadas mais tarde".

5 Pseudônimo da dramaturga francesa Marie Gouze (1748-1793), ativista política que se lançou na defesa da democracia e do direito das mulheres, escrevendo várias obras, dentre as quais se destaca a Declaração dos direitos da mulher e da cidadã, publicada em 1791.

${ }^{6} \mathrm{Na}$ nota 2 da página 21 de seu livro $A$ vindication... a autora afirma que no livro V do Emílio se apresenta um plano de educação da mulher. O que é, a meu ver, um erro de leitura da autora inglesa, uma vez que Sofia não fora educada por Jean-Jacques, o preceptor, mas por sua família, numa clara alusão à educação aristocrática ou pequeno-burguesa de seu tempo.

${ }^{7}$ Como informa Badinter (2003, p. 366), "Louise perseguia um duplo objetivo: traçar o retrato da boa mãe e o retrato do modelo feminino que ela sonhava ver desenvolvido". Mas exagera quando diz que: "Madame d'Épinay se apresenta como uma rival de Rousseau no terreno da pedagogia". N'As conversações há, certamente, críticas contra algumas propostas rousseaunianas, mas não uma oposição sistemática ou uma alternativa ao conjunto de ações pedagógicas que compõem o pensamento educacional encontrado no Emílio, fazendo dela uma "rival".

${ }^{8}$ Basta lembrar o panfleto de John Stuart Mill (1806-1873), A sujeição das mulheres, no qual retoma algumas questões trabalhadas por Wollstonecraft, e denuncia: "Todas as mulheres são, desde a mais tenra infância, criadas na crença de que o seu ideal de caráter é diametralmente oposto ao dos homens: não vontade própria e capacidade de governarem autonomamente, mas submissão e rendição ao controle dos outros" $(2006$, p. 60).

${ }^{9}$ Louise Florence Pétronille Tardieu d'Esclavelles d'Épinay (1726-1783), escritora francesa que mantinha um forte laço intelectual com Rousseau, Diderot, d'Alembert, Grimm, entre muitos outros que frequentavam seu salão literário. Autora da premiada obra Conversations d'Émilie (1774), escrita para a educação de sua neta, além de uma autobiografia com as correspondências com os amigos. Compartilhava com Rousseau, a quem conhecera em 1748, muitas de suas ideias, como a da religião natural, do aleitamento materno e dos cuidados da criança.

${ }^{10}$ Marie-Charlotte Hippolyte de Boufflers (1725-1800), uma "femme de lettres" que se tornou uma das principais anfitriãs nos salões literários. Amiga íntima tanto de Hume quanto de Rousseau, tentou apaziguar os ânimos entre os dois, durante a grande querela entre ambos (Vide ZARETSKY \& SCOTT, 2009).

11 Jeanne Quinault (1699-1783), atriz e dramaturga francesa que dava conselhos aos intelectuais, inclusive a Voltaire e a Rousseau. 
12 Como afirma Goodman (1989, p. 333), “O objetivo inicial e principal por trás dos salões era o de satisfazer as necessidades educacionais autodeterminadas das mulheres que os iniciaram”.

13 Jeanne-Antoinette Poisson (1721-1764), Marquesa de Pompadour, foi amante do Rei Luis XV e deteve um poder político ao ponto de governar Versailles em lugar do monarca.

14 Joseph-François-Édouard de Corsembleu Sieur de Desmahis (1723-1761), dramaturgo francês amigo de Voltaire, o qual contribuiu com a Enciclopédia.

${ }^{15}$ Ensaio sobre o caráter, os costumes e o espirito das mulheres em diferentes séculos.

${ }^{16}$ Que ela chama de "pomposo palavratório, bem eloquente, um tanto pedante, e muito monótono" que não chega a nenhuma conclusão (THOMAS, 1991, p. 135/136). E quem a chama de "ambiciosa" é Badinter (2002, p. 331).

${ }^{17}$ Um legado de um pai para suas filhas.

${ }^{18}$ François de Salignac de La Mothe-Fénelon (1651-1715). Teólogo católico, poeta e escritor francês, cujas ideias educacionais mesmo conservadoras contrariaram os princípios da Igreja e do Estado.

${ }^{19}$ Mary Wollstonecraft foi mãe de Mary Shelley (1797-1851), autora do livro Frankenstein.

${ }^{20}$ Embora o faça de forma branda e poética, dizendo: “O império da mulher é um império de doçura, de habilidade e de complacência; suas ordens são carinhos, suas ameaças são lágrimas. Ela deve reinar na casa como um ministro de Estado, fazendo com que comandem o que quer fazer. Neste sentido os lares mais felizes são em geral aqueles em que a mulher tem mais autoridade: mas quando ela despreza a voz do chefe, quando quer usurpar os direitos dele e mandar sozinha, o que resulta da desordem é miséria, é escândalo, é desonra" (1973, p. 480).

${ }^{21}$ Vide o "Episódio das Favas”, no Livro II do Emílio (ROUSSEAU, 1973, p. 85-89)

22 "Sócrates - Estou vendo, amigo, que Teodoro não ajuizou erradamente tua natureza, pois a admiração é a verdadeira característica do filósofo. Não tem outra origem a Filosofia”. (PLATÃO, 2001, p. 55).

${ }^{23}$ Talvez a motivação maior tenha sido o ataque de Burke às pregações de Richard Price (1723-1791), filósofo moral e pregador religioso, líder do grupo dissidente Rational Dissenters, do qual Wollstonecraft participou. Para ela, Burke foi injusto contra uma pessoa de "excelência moral" e uma "mente benevolente" (1996, p. 31).

${ }^{24}$ Como fez em sua carta a Edmund Burke (1729-1797), dizendo: "Eu respeito um oponente, mesmo que ele mantenha tenazmente sua opinião com a qual eu não concorde” (WOLLSTONECRAFT, 1996b, p. 48). Ela concorda com Rousseau em alguns pontos, como a liberdade natural, a artificialidade do teatro, a tensão entre natureza e cultura, entre outros; e esclarece que sua luta não é contra a pessoa de Rousseau, mas "contra as ideias" (WOLLSTONECRAFT, 1996, p. 93) com as quais não concorda.

25 Charles Maurice de Talleyrand-Périgord (1754-1838), diplomata francês que apresentou o Rapport sur L'Instruction Publique, fait au nom du Comité de Constitution.

${ }^{26}$ Embora Mackenzie (2016, p. 11) comente que: "ser guiado pela razão é apenas uma parte do caráter virtuoso. Adquirir virtude não é apenas uma questão de ampliar a mente, mas também de expandir o coração, o que requer uma capacidade de afeição, de amizade e de manutenção de paixões fortes".

${ }^{27}$ Mas também no próprio Rousseau quando diz no Emílio (p. 134): “a descoberta da causa do mal indica seu remédio". Bem como no Segundo Discurso (1999, p. 300): "Esse simulacro consiste numa certa doçura de costumes que algumas vezes substitui sua pureza, uma certa aparência de ordem que previne a tremenda confusão, uma certa admiração pelas belas coisas que impede as boas de caírem inteiramente no esquecimento. É o vício que toma a máscara da virtude, não como a hipocrisia para enganar e trair, mas para, sob essa efígie amável e sagrada, afastar o horror que tem de si mesmo quando se contempla nu".

${ }^{28}$ Cf. o testemunho de Marmontel in Mémoires, edição crítica organizada por J. Renwick. G. de Bussac. ClermontFerrand, 1972, vol. I, p. 309. 
${ }^{29}$ Amparando-se na leitura do Livro V do Emílio, Pissarra (2002, p. 72) afirma que, quanto a isso, “é difícil aceitar hoje a visão que nosso autor tem das mulheres - embora totalmente de acordo com seu tempo, é bom frisar! A mulher é inferior porque a natureza a fez mais fraca, sendo, portanto, natural que ela obedeça ao homem. Educada pela ótica masculina - seu pai ou seu marido -, a mulher tem menos liberdade, aceita com mais facilidade a opinião dos outros, é também menos privilegiada intelectualmente".

${ }^{30}$ Como informa o tradutor das Conversações para o inglês (1787), prefácio da obra.

${ }^{31}$ Dionísia Gonçalves Pinto (1810-1885), cujo pseudônimo foi Nísia Floresta, publicou em 1832, em Pernambuco, o que pode ser considerado uma versão livre da obra $A$ vindication of the rights of woman, de Wollstonecraft, o qual saiu com o título: Direito das mulheres e injustiça dos homens.

32 Como diz Larrère (2012, p. 98), “A Nova Heloísa é um verdadeiro romance de formação, um Bildungsroman, onde, através dos obstáculos que ela encontra, Júlia inventa sua liberdade”.

\section{Referências:}

AUSTEN, Jane (2009). Razão e Sensibilidade. São Paulo: Martin Claret, 2009.

BADINTER, Elisabeth. Émilie, Émilie: a ambição feminina no século XVIII. Trad. Celeste 
Marcondes. São Paulo: Discurso Editorial: Duna Dueto: Paz e Terra, 2003.

BERNIER, Oliver. The Eighteenth-century woman. Garden City: New York: Doubleday \& Company Inc., 1981.

BURKE, Edmund. Reflexões sobre a Revolução na França. Trad. apres. e notas de José M. N. Soares. São Paulo: EDIPRO, 2014.

DAMROSCH, Leo. Jean-Jacques Rousseau: restless genius. Boston: New York: Houghton Mifflin Company, 2007.

DERATHÉ, Robert. Jean-Jacques Rousseau e a ciência política de seu tempo. Trad. Natália Maruyama. São Paulo: Editora Barcarolla: Discurso Editorial, 2009.

DIDEROT, Denis. Enciclopédia, ou Dicionário razoado das ciências, das artes e dos ofícios. V. 5: Sociedade e artes. Trad. Maria das Graças de Souza (et al.). São Paulo: Editora Unesp, 2015 .

. Sur les femmes. Paris: Léon Pichon, 1919.

EPINAY, Louise Tardieu d'Esclavelles. Les conversations d'Émilie. (2 volumes) Paris: Chez Humblot, 1781.

. The conversations of Emily. Translated from the French of Madame la Comtesse d'Epigny. In two volumes, vol. 1 (London: John Marshall and Co., 1787) ix.

FÉNELON, François. De l'éducation des filles. 1687. 2a. ed. Paris: Librairie Achette et Cia., 1909.

FLORESTA, N. Direitos das mulheres e injustiça dos homens. São Paulo: Editora Cortez, 1989.

GOODMAN, Dena. Enlightenment Salons: The Convergence of Female and Philosophic Ambitions. Eighteenth-Century Studies, Vol. 22, No. 3, Special Issue: The French Revolution in Culture. (Spring, 1989), pp. 329-350.

2009.

. Becoming a woman in the age of letters. Ithaca and London: Cornell University Press,

GOUGES, Olympe de. Declaration des droits de la femme et de la citoyenne. 1791. http://www.siefar.org/wp-content/uploads/2015/09/Gouges-Déclaration.pdf. Acessado em 17C08/2017.

GOUNCOURT, Edmond et Jules de. La femme au dix-huitième siècle. Paris: EJG, 1862.

GRACE, Eve \& KELLY, Christopher. Rousseau on women, love, and family. Hanover: London: University Press of New England, 2009. 
GRÉARD, Octave. L'éducation des femmes par les femmes. Troisième édition, Paris: Hachette, 1889.

GREGORY, John. A father's legacy to his daughters. London: Wood \& Innes, 1808.

LANGE, Lynda (org.). Feminist interpretations of Jean-Jacques Rousseau. Pennsylvania: The Pennsylvania State University Press, 2002.

LARRÈRE, Catherine. Locke et Rousseau: la place de femmes. In Annales de la Société JeanJacques Rousseau, T. V, Genève: Droz, 2012.

L'AMINOT, Tanguy. La critique féministe. In: CLARK, Lorraine \& GUY, Lafrance (editors). Rousseau and cristicism/Rousseau et la critique. Pensée Libre, n. 5. Ottawa: 1995.

LEME, Violeta. O calvário de uma professôra. 2a. edição. São Paulo: Gráfica Mercúrio, 1952.

LOMBROSO, Gina. La femme dans la société actuelle. Paris: Payot, 1929.

MACKENZIE, Catriona. Mary Wollstonecraft: An Early Relational Autonomy Theorist? In: BERGÈS, Sandrine and COFFEE, Allan (eds.) The social and political thought of Mary Wollstonecraft. Oxford: Oxford University Press, November 2016 , pp. $183-200$.

MARMONTEL, Jean-François. Mémoires de Marmontel, avec préface, note e table par Maurice Tourneau. Paris: Librarie des bibliophiles, 1891, vol. I.

MILL, Stuart. A sujeição das mulheres. Coimbra: Almedina, 2006.

OZOUF, Mona. Women's words: essay on French singularity. Chicago \& London: The University of Chicago Press, 1997.

PAIVA, Wilson Alves de. Progresso e depravação: a cultura como remédio. Revista Kriterion, Belo Horizonte, no 134, Ago./2016, p. 421-440.

PIAU-GILLOT, Colette. Le discours de Jean-Jacques Rousseau sur les femmes, et sa réception critique. In: Dix-huitième Siècle, $\mathrm{n}^{\circ} 13,1981$. Juifs et judaïsme. pp. 317-333; doi : https://doi.org/10.3406/dhs.1981.1346 https://www.persee.fr/doc/dhs_007067601981 num 13 1_1346. Acessado em 20/03/2018.

PISSARRA, Maria Constança Peres. Rousseau - a política como exercício pedagógico. S. Paulo: Moderna, 2002.

PLATÃO. Teeteto - Crátilo. Trad. Carlos Alberto Nunes. 3a. ed. rev. Belém: EDUFPA, 2001. . A República. Tradução de Enrico Corvisieri. São Paulo: Editora Nova Cultural, 2004. (Coleção Os Pensadores)

RICOEUR, P. A memória, a história, o esquecimento. Tradução de Alain François [et al.]. Campinas, SP: Unicamp, 2007. 
ROUSSEAU, Jean-Jacques. Oeuvres complètes. 4v. Paris: Gallimard, 1964. (Bibliothéque de la Plêiade).

. Emílio ou da educação. São Paulo: DIFEL, 1973.

Discurso sobre a origem e os fundamentos da desigualdade entre os homens. São Paulo: Nova Cultural: 1999. (Coleção Os Pensadores - Rousseau - Vol. II).

. Júlia ou a Nova Heloísa. Trad. Fulvia M. L. Moretto. 2a. ed. São Paulo: Editora Hucitec, 2006.

. Emile e Sophie ou os solitários. Edição bilíngüe (francês e português). Trad. Dorothée de Bruchard. Porto Alegre: Editora Paraula, 1994.

SOUZA, Cristiane Aquino de. A desigualdade de gênero no pensamento de Rousseau. Revista Novos Estudos Jurídicos. Vol. 20, n. 1, jan-abr. 2015.

STAROBINKSI, J. As máscaras da civilização: ensaios. Trad. Maria Lúcia Machado. São Paulo: Companhia das Letras, 2001.

THOMAS, Antoine Léonard. O que é uma mulher?: um debate/A. L. Thomas, Diderot, Madame d'Epinay. Pref. Elisabeth Badinter; trad. Maria H. F. Martins. Rio de Janeiro: Nova Fronteira, 1991.

THOMAS, Keith. O homem e o mundo natural. São Paulo: Companhia das Letras, 1988.

VOLTAIRE. Dicionário filosófico. Os pensadores. Rio: Editora Abril, 1973.

WOLLSTONECRAFT, Mary. A vindication of the rights of woman. Mineola: New York: Dover Publications Inc., 1996. . A vindication of the rights of men. New York: Prometheus Books, 1996.

. Thoughts on the education of daughters: with reflections on female conduct in the more important duties of life. London: Kessinger Legacy Reprints, 1787.

ZARETSKY, Robert \& SCOTT, John T. The philosophers' quarrel: Rousseau, Hume, and the limits of human understanding. New Haven and London: Yale University Press, 2009. 